\title{
Exploring the impact of freeform gameplay on players' experience: an experiment with maze games at varying levels of freedom of movement
}

\author{
Sotiris Kirginas ${ }^{1}$, Dimitris Gouscos ${ }^{1}$ \\ National and Kapodistrian University of Athens \\ \{skirginas,gouscos\}@media.uoa.gr
}

Abstract

This paper describes an experiment which aims to examine whether different versions of the same game, which differ only in terms of freedom of movement that incurs varying degrees of freeform gameplay, elicit different kinds of player experiences. Seventy one children aged 9 and 11 from a Greek primary school participated in a research experiment with these different game versions. Post-tests were used to measure the children's opinion of these games and differences in the appeal of the versions were then attributed to the feature of freeform gameplay. The findings from the study demonstrated that the digital game that offers the greatest extent of freeform gameplay led to better gaming experience than the digital games with lower extent of freeform gameplay. The main contribution of the paper, therefore, is that the research conducted provides some evidence that freeform gameplay is an important factor of positive gaming experience, and as such it should be optimized. This can only be done by considering at the same time the cognitive capabilities and pre-existing skills and knowledge of users, in the sense that only a level of freeform gameplay harmonized with user capabilities can lead users to learn, which is the ultimate goal of serious games.

Keywords: Game experience, Engagement, Flow, Freeform game, Level design, Serious Game

\section{Introduction}

In a previous exploratory study [1] it was found that there is a direct correlation between the quality of players' experience and the kind of play that a digital game offers, depending on whether the latter focuses on the game dimension (structured games) or the play dimension (freeform games) of gameplay. More specifically, from that study we concluded that players feel less stressed when playing a freeform digital game, they feel happier and more engaged and find this kind of games more pleasant and exciting. However, that study based on digital games with different game elements, such as the game story, the aesthetics of the game world, the winning or losing states, the reward and score system, as well as the interaction mechanisms with the game world elements [2-6].

The motivation of the present research was to examine whether different versions of the same game, which differ only in the degree of freeform gameplay elicit different kind of player experiences. To this end, our research design has been based on the construction of a maze game with varying degrees of freedom of movement, which creates varying degrees of freeform gameplay as well, the latter resulting both from the freedom of movement itself and from the freedom of game tactics that this freedom of movement allows. In this respect, an initial structured maze game with lower degree of freedom of movement and freeform gameplay was developed, accompanied by a semi-structured variant of the same maze game with higher degree of freedom of movement and freeform gameplay, and a final freeform game with even greater degree of freedom of movement and freeform gameplay. In this way, we attempted to neutralize all other factors that would differentiate the three games apart from the degree of freedom of movement and freeform gameplay incurred, in order to explore whether more and more freeform gameplay in digital games is always better in terms of the player experience that it results in.

The work described in this paper forms part of a broader research effort which aims at exploring correlations between game structure and player engagement of primary school children, and find optimal relationships between these two variables; with a view to integrating digital games in 
educational settings, the research aims to identify if there are significant correlations between the quality of players' engagement and the kind of play that a digital game offers, depending on whether the latter focuses on the game dimension (formally structured games) or the play dimension (freeform games) of gameplay.

The rest of the paper is organized as follows: Section 2 gives an overview of theory in the field of freeform play and existing methods of evaluating gameplay experience. Section 3 describes the research design and the data collection methods used in this research. Section 4 presents the main research findings. Section 5 offers a discussion and Section 6 some concluding remarks.

\section{Background concepts and research}

\subsection{The concept of freedom of choice}

The idea that freedom of choice is a primary factor for leading a good life is not a new one. Given this, it is easy to understand the significance of freedom of choice to evaluate the kind of gameplay.

In the literature review, there are two different ways of viewing freedom each of which has been explored by scholars over a long time. According to the first approach [7], there is a "positive" view of freedom, focus on what a person can choose to do or achieve, rather than on the absence of any particular type of restraint that prevents him or her from doing one thing or another; according to the second approach, there is a "negative" view of freedom focuses precisely on the absence of a class of restraints that one person may exercise over another, or indeed the state may exercise over individuals [8]. It is clear that both approaches have much to offer for assessing the freedom of gameplay.

According to Klopfer et al [9], freedom in play is presenting along five distinct axes: freedom to fail; freedom to experiment; freedom to fashion identities; freedom of effort; and freedom of interpretation. Generally, according to Björk and Holopainen [10] freedom of choice can be achieved within three different areas in relation to games. Firstly, players may have choices to do with rules as a part of the gameplay. Secondly, they may have choices on which actions to perform as part of the gameplay to affect the outcome of the game. Thirdly, they may have choices to be engaged in other types of activities while gameplay progresses. An important aspect of designing for freedom of choice in gameplay is to be aware that the allowing players several different ways of affect game states is not the most critical issue; it is that they perceive they have it. Furthermore, as Sid Meier rightly argues, "a good game is a series of interesting choices". In an interesting choice, no single option is clearly better than the other options, the options are not equally attractive, and the player must be able to make an informed choice [11]. Actually, a player cannot win a game without a strategy and strategy manifests itself as a series of interesting choices [4].

Furthermore, choices without consequences are meaningless, a waste of time, effort and money [12]. Whenever a player makes a choice this can be a "good" or a "bad" choice depending on the consequences that follow it. There are "good" choices, which reward players" knowledge or good strategy and help them to improve their gaming experience, as well as "bad" choices, which penalize lack of knowledge or bad strategy. Still, in a game world, even making "bad" choices is meaningful, as this allows players to try and make mistakes or fail, and then try again without any negative real-world consequences.

That said, though, the real-world counterpart of "good" and "bad" choices within a (serious) game, is an independent issue. Game designers may decide to present as good choices (in the ingame sense of the term) decisions which would not be acceptable in the real world (e.g. earning points through violence) and vice versa (e.g. losing points by following a non-selfish strategy). This is an issue that we are not pursuing further in the context of this research, given that our focus stays centered on the consequences that the presence (or absence) of in-game choices (and thus, of in-game freedom of choice) can have for the quality of player experience, rather than on the consequences that an attempt to transfer such choices in a real-world setting may imply.

It is important, at this point, to shed light on the relation between game usability and freedom of choice. There are a variety of factors that affect the usability of games (game interface, game mechanics, visibility of game status, consistency and standards, flexibility and efficiency and others). Still, freedom of choice is a concept related to usability, that gives to players the possibility to decide on their own strategy, how to move, what direction to follow, what accessories to use, what challenge to choose for trying to overcome at any given point and so on. In this sense, 
freedom of choice is a characteristic that results in freeform gameplay, and freeform gameplay is not really possible without some degree of freedom of choice. At the same time, given that an essential feature of playing is the movement of the player in the game world, freedom of movement, as a special kind of freedom of choice, is affecting freeform gameplay and usability.

What are the game design elements that make up for a really freeform game? There is no definitive and commonly accepted answer to such a question. Based on findings of our previous studies we have come up with some proposed answers for what makes a game freeform, and below we present some of these. The list of aspects below cannot be considered as a complete and closed one. Yet, in our view, all aspects included in this list play an important role in making up a freeform game.

(a) Non-linear gameplay

Non-linear gameplay means that games provide choices for players to make, different paths that the players can take to get from one point to another, from the game's beginning to its end. On the contrary, linear gameplay means that players have to follow a single path to one objective and there are no alternate paths or methods for accomplishing this objective [13]. Players learn new things in the appropriate order and developers can make sure everything goes as pre-designed.

(b) Selection of challenges

Freeform games allow players to choose which challenges they want to overcome or not. From a games for learning perspective, in particular, such games can result in improving students' learning by increasing their interest due to the pleasant and attractive environment that they offer, often contrary to conventional learning environments. On the contrary, structured games have structured activities which confront players with a pre-defined set of challenges, that all need to be overcome [14]

(c) Multiple solutions to the game challenges

Freeform games allow multiple solutions to the game challenges and enable many different player-generated gameplay paths. Not every player will go about solving a situation in the same way and, given that these alternate solutions are reasonable, almost any challenge must have multiple ways for players to overcome it [14]. Structured games offer unique solutions to challenges (every player overcomes a challenge in the same way) and this does not allow players to come up with different ways to proceed in the game.

(d) Free sequence of challenges

In freeform games, players have the ability to choose the order in which they face challenges. Giving players choices of different challenges to overcome allows them to put aside a difficult challenge and occupy themselves with another one for a while. After completing the second challenge, players may return to the first gratified and less stressed/better concentrated, and thereby stand a better chance of overcoming it. On the contrary, structured games have structured designer-generated activities which confront players with a fixed sequence of challenges. Games with a fixed sequence of challenges allow players access to only one challenge at a time. In order to even attempt a second challenge, players must complete the first one. This is especially frustrating when players cannot overcome a particular challenge and can do nothing else until that challenge is successfully met.

It should be noted, at this point, that in the research reported in this paper we are trying to explore a specific type of freedom of choice in games, that of freeform gameplay. Moreover, we are trying to explore freeform gameplay through one of its most simple manifestations within digital games, that of a maze game in which freeform gameplay is practically manifested as freeform movement. Still, given that movement has not just to do with change of location, but also with strategies for getting closer to or more away from a goal (fruits to eat, in the maze game of our research design), we believe that freeform movement in this case can be considered as an effective manifestation of freeform gameplay.

\subsection{Freeform and formally structured digital games: Brief overview of current studies}

Game play has been thought in game studies to be by definition a special kind of a formalized subset of action, within various "ludic activities", which in turn were placed within the even more general category of "being playful" [5].

Fundamental to the discussion of rules and freedom in play is the distinction Roger Caillois [15] introduced by identifying two forms of play, ludus (structures, rules, goals and limits) and paidia (more unstructured, spontaneous and free act of play). 
Gonzalo Frasca [16] has developed Caillois' theory further and noted how certain games are more clearly designed for a formally defined ludus gameplay - they are typically focused on winning and losing, the counting of points, and they generally provide players with clearly defined goals during gameplay. In contrast, games designed with more open goals, exploration, experimentation and improvisation in mind are more likely to invite a paidia style of free, playful behaviours. As MacGregor [17] notes, using Frasca's understanding of Caillois terms, the spectrum between paidia and ludus in relation to digital games operates between ludus as a structured goal-driven type of activity, with clearly defined or formalised rules, and paidia as a freeform type of activity, with undefined goals and undefined but implicit or informal cultural rules.

Bateman [18] describes paidia as an amusing, creative and chaotic activity, but also shortlived as it soon becomes a game (and thus ludus). As an example of a paidia game he mentions Sink; a natural play activity played close to a large body of water. It consists of throwing something that floats into the water and trying to sink it by throwing another thing at it. Bateman sees play as a journey from paidia to ludus and vice versa. For instance, when temporarily escaping from the rules of ludus, one can move back to paidia. To support paidia, no complex learning should be involved and players have to be encouraged to experiment.

At about the same time, Jesper Juul [19] argued that most digital games can be found on a scale between emergence and progression, and their game guides are consequently a combination of step-by-step descriptions and strategy guides. Emergence games are historically the oldest: consisting of a limited set of rules they allow for a great number of game variations. This pattern underlines all card and board games, action and strategy games and multiplayer games. Progression games are newer forms. They are adventures based on a set of instructions that must be followed to reach the end of a game. This type of game resembles storytelling and can be played only once. Once you've reached the end the game is over.

Konstantin Mitgutsch [20] recently noted that while a number of digital games focus on the game-dimension of game play, such as rules, goals and structures (referred to as ludus [4] there are other digital games that focus on the play-dimension of game play, such as unstructured, spontaneous and free act of play (referred to by Caillois as paidia).

In their work on the free play in open-ended interactive art environments, Morrison et al. [21] define free play as "non-narrative, non-competitive, and without logical ending point". The play is kept alive as the ending point continually evolves. This relates to Carse's [22] work on finite and infinite games. The aim of a finite game is winning the game, while an infinite game is played only for the purpose of continuing the play. Morrison et al. mention the followings two aspects of free play. First, it is constantly rejuvenated as it is co-constructed and co-authored by its participants. They are in control of discovering what the design has to offer them. Secondly, it is freeform any predetermined order of meaning. People construct their own meaning and invent their own interpretations from interacting with the design

On this basis it may be concluded that digital games categories can be considered to lie at various points on an axis of play between totally freeform activity and formally structured goaldriven activity:

The "formally structured" end of the axis focuses on the game-dimension of game play, such as rules, goals and structures. Games that would lie at this end comprise "formally structured" digital games which are more strictly defined since (a) they have an explicit set of winning and losing rules which force players to take specific paths to reach goals and ensure that all players take the same paths; (b) they have pre-determined and clear goals whether these are to beat players' high score, progress to the next level or complete the game in full, etc.; (c) they provide immediate feedback which lets players know immediately whether what they have done is positive or negative for them in the game, whether they are staying within or breaking the rules, moving closer to the goal or further away and how they are doing versus the competition; (d) they have structured designer-generated activities with linear gameplay which confront players with a fixed sequence of challenges; and (e) they have a defined space and time which include any narrative or story elements in the game.

The "freeform" end of the axis focuses on the play-dimension of game play, such as unstructured, spontaneous and free acts of the play. Games that would lie at this end comprise "freeform" digital games that (a) have no set of rules pre-determined by the game designers or if there are rules they are informal and flexible and the player has freedom to use them or not; (b) exhibit no pre-defined goal but accommodate players' goals that are entirely intrinsic and personal; (c) have no "winning plot", as they are more open-ended; and (d) include nonlinear gameplay which allow greater player freedom than games with linear gameplay. In freeform games the 
players have more freedom to decide what to do, to set their own individual goals and determine their rules, path, scenario and plot. As there is no system of rules that defines a victory or a defeat, a gain or a loss, the players' aim is not to win but rather to learn the game through exploration and discovery play. The players are in effect the authors of the play and goals in digital games of this category, and this is the only decision made for the players by the game designers in regard to the players.

\subsection{Educational significance of freeform games}

The notion of freeform games can include both games developed for entertainment purposes as well as, serious games, namely games developed for educational purposes [23]. Several effective freeform serious games have (a) a spatial organization, namely the virtual world where learning is distributed and that induces spatial information processing and provides landmarks to support orientation and (b) contextualized tasks that are spread and contextualised in the virtual worlds, which tend to support players in building a suited knowledge structure for the addressed topic [2428].

We are particularly concerned with serious games in the sense that these games, no matter if addressing education or other domains, have an explicit learning purpose. We speculate that if serious games uptake the characteristics of freeform play they can lead to more engaging gameplay. When students play with freeform serious games, they feel more motivated and engaged. Students in such an environment have the freedom to determine their own learning paths via goals and rules. The negative emotions and frustration caused by failure are weakened, exactly because success can be subjectively defined by the players themselves. This, however, does not mean that frustration is always negative. In fact, frustration can have both positive and negative impacts on gaming experience [29]. As mentioned in the literature, a digital game can induce frustration but in many cases it can still remain challenging and appealing [30]. In our point of view, freeform games allow players to discover new skills, try and make mistakes or fail, and then try again without any negative real-world consequences; this reduces negative frustration. In such cases, a sense of continued engagement and intrinsic motivation can be sustained during gameplay especially when, according to Malone \& Lepper [31], games include representations of the real world and involve the players' fantasy. Fantasy can offer analogies or metaphors for real-world processes that allow players to experience the same phenomenon from different perspectives. That means that skills may be learnt more easily when presented within an imaginative context rather than in a conventional learning environment, and if this context can be explored in more freeform ways this could create increased motivation to keep playing the game, thus increased exposure to the game over time, thus increased possibility for learning.

That said, it should be stressed that the approach of freeform gameplay for serious games needs to be integrated with other learning approaches and principles. Besides the concept of freeform gameplay, which leads to the concept of freedom of choice, there is also the concept of limit, which is very important, especially in the real-world, so key in learning processes. Too much freedom of choice within a game could indeed make players spend an overly extended amount of time exploring the game world without a particular purpose, thus risking to become lost and frustrated, in case the rest of the game elements (especially the elements contributing to fantasy, in the sense of this term by Malone, such as the game story, the aesthetics of the game world, as well as the interaction mechanisms with the game world elements) do not offer an experience which compensates their time investment [32]. Freedom of choice seems to be important in making digital games appealing, but it is not clear how to design serious games in which freeform gameplay leads to efficient learning. In other worlds, freedom of choice is important, and so is the structure of the game. Ignoring the second can lead to aimless play; ignoring the first can lead to a serious game that most students fail to assimilate or understand [33, 34].

On top of that, from a serious game point of view, as noted by researchers like Kirschner et al. [35], unguided discovery is more often than not inefficient due to the structures that constitute the human cognitive architecture. Therefore, from a learning purpose standpoint, it may be better to consider that freeform games could best be integrated into more structured instructional scenarios, in order for tutors to be able to more effectively lead the learning process.

\subsection{User experiences based on different versions of a game}

Digital games are widely considered as high potential educational tools able to provide students with new augmented learning opportunities [34]. However, learning outcomes are a common but 
not the only potential game's effectiveness. In this case, we performed a literature review in order to examine how different versions of a game influence users' experiences.

Malone [33, 34] in order to see which of three features of Breakout game - the score, the breaking out of the bricks, and the ball bouncing off the paddle - was most important in the appeal of the game, constructed six different versions of the game varying the three features in all sensible combinations. Each subject played with each version of the game and, at the end of the session, the subjects were asked to rate each version. The results showed that a partially destroyed wall of bricks presents a visually compelling fantasy goal and, at the same time, is a graphic scorekeeping device telling how close the player is to attaining that goal. It thus provides a goal, a visual effect, fantasy, and scoring all at the same time. The results also showed that the versions that had neither a score nor bricks breaking out were significantly less appealing than the other versions. In other words, the versions in which there were no clear goals were significantly less fun than the others.

In another study Malone [33, 34] constructed eight different versions of the game Darts, each of which had one more presumably motivational feature than the last in order to find out which of motivational features such as feedback, music, and graphics, contribute most to the appeal of the game. Each student was assigned to one condition and was allowed to choose freely between the version of Darts in that condition, and a version of the Hangman computer game that was the same in all conditions. Students were able to change back and forth between the two games as often as they wanted during two 20 minute sessions. Then students were asked to say which game they liked the most and to rate each game. The result of this experiment was that boys liked the fantasy of arrows popping balloons, and girls appeared to dislike this fantasy. The results also revealed that fantasy made more difference in the appeal of the game than did simple feedback. Even though responsiveness is considered as an important feature for a game to be captivating, the simple feedback was not as important as the fantasy in making this game fun.

Focusing on the comparison of time on task for the intrinsic and extrinsic versions of Zombie Division, Habgood [36, 37] conducted a study over three weekly sessions lasting forty-five minutes each as part of an after-school computer club. Fifty-eight pupils took part in the study, comprising an entire 7-8 year group topped up with students picked by their class teacher from the year below. Throughout the study participants were allowed to freely switch between the intrinsic and extrinsic versions of the game without suffering any overall loss of progress. The order of the game selection was randomized. Participants were initially presented with the two versions of the game running side-by-side and asked to make sure that they tried playing both versions during the club. They were also free to choose to do their usual club activities instead (just about any activity available on the school PCs). In a fourth club session, the pupils were interviewed about their experiences and asked to describe the differences between the two versions. The results revealed that children had a clear preference for the intrinsic version of the game, but the interview data showed a more complicated set of motivations behind this choice. Competition within the group was clearly a strong motivating factor and some children felt that it was quicker to progress through levels in the intrinsic version of the game (as the quiz took additional time). Nonetheless, it was clear from some of the other comments that they possessed a surprisingly deep understanding of the design choices used in the two versions and one even astutely described the intrinsic version of the game as "like subliminal learning with maths".

In summary, a limited number of studies attempted to examine which of game features contribute most to the user's enjoyment. All these studies were conducted through different versions of games varying the various features in all sensible combinations. Self-reported questionnaires or time-on-task measures were used as the principal measure of users' experiences. The design and the methodologies used in these studies have formed the basis on which our study has been developed.

\section{Research Method}

\subsection{Research focus and questions}

As mentioned before, in the study reported in this paper, we are focused on exploring freeform gameplay, as a specific type of freedom of choice in games. To this end, we have attempted to explore whether or not three different versions of the same game, which differ only in the degree of freeform gameplay, elicit different kind of gameplay experiences. More specifically, we attempted to neutralize all these factors that differentiate the majority of games apart from the extent of freeform gameplay in order to explore whether more and more freeform gameplay is always better 
or, in other words, should the objective of serious game design be to maximise freeform gameplay at all costs? From our research experience thus far, we feel this may not be the case; too less freeform gameplay may indeed deprive players of interesting challenges, whereas at the same time too much freeform gameplay may deprive them of interesting constraints which, like challenges, play an integral role in the emergence of engagement. Furthermore, we attempted to correlate the game competence level of our subjects to the extent of freeform gameplay of their preferred games. From our previous experience, we believe that novices or younger players and females have a tendency to follow the rules when playing games as they have yet to acquire the context in which those rules operate. As they grow in competency to play a game, they will learn to apply the right rules with the right conditions. Expert or older players as well as males, on the other hand, tend to ignore or even freely break the rules.

Based on the above objectives we formulate the following research hypotheses:

H1: Different versions of the same game, which differ only in the extent of freeform gameplay, will lead to a different gaming experience.

$\mathrm{H} 2$ : From the different versions of the same game, which differ only in the extent of freeform gameplay, the one that offers the greatest extent of freeform gameplay will lead to a better gaming experience.

H3: The impact of different versions on students' experience will differ across sex, age, frequency of digital game use and gaming experience.

H4: There will be a statistically significant correlation between the variables of game features and children's preference.

\subsection{Design of the research process}

The design of the present study was within-subjects single factor with three versions: structured game (G1), semi-structured game (G2) and freeform game (G3). The subjects were told that the objective of all three versions was to collect fruits and avoid hamburgers. Then each subject played with each of the three versions of the game for about 20 minutes, over two weekly sessions lasting sixty minutes each. Subjects played the games in all possible series combinations (G1G2G3, G1G3G2, G2G1G3, G2G3G1, G3G1G2 and G3G2G1). At the end of the second session, the subjects were asked to rate the games for player satisfaction using and gaming experience three data collection instruments (Smileyometer, Fun Sorter Table, Again-Again Table). Finally, the subjects were asked to report which feature they liked the most about their favorite game.

\subsection{Participants}

There were 71 children ( 45 boys, 26 girls) at the age of 9 to 12 years old that took place in the experiment with an average age of $10.44(\mathrm{SD}=1.16)$. From these children, 20 were in the third grade, 18 in the fourth grade, 15 in the fifth grade and 18 in the sixth grade (Table 2). The children were all from a Primary School located in Athens, Greece. In the beginning of a validation study, the purpose and procedure of the study were described to the children. Children then asked to provide their demographic data: age, gender, game experience and frequency of play. All the subjects had played computer video games before the experiment. Children were surveyed on their use of digital games and totally $69 \%$ of them play digital games more than 3 years. More than 52 percent of the students (37) use games every day, 35.20\% (25) use games rare and $12.70 \%$ (9) once a week.

Table 2: Age and sex of participants

\begin{tabular}{c|c|c|c}
\hline Age & Male & Female & Total \\
\hline 9 & 13 & 7 & 20 \\
\hline 10 & 11 & 7 & 18 \\
\hline 11 & 11 & 4 & 15 \\
\hline 12 & 10 & 8 & 18 \\
\hline Total & 45 & 26 & 71 \\
\hline
\end{tabular}




\subsection{Games Used in the Research}

To examine the effect of freeform gameplay in the players' experience, three digital games were constructed, in which the extent of freeform gameplay was designed to systematically vary. The main idea of the games resembled a classic game that could be played on a desktop computer. The game is comprised of fun and interactive means to familiarize students on the health and healthy diet with and special attention was focused on familiarizing children with healthy food and nutrition value of food. A virtual avatar could interact within a virtual game world and points could be earned by selecting a variety of fruits, earning points. The avatar should avoid burgers, otherwise, she would lose a life. If all fruits were selected within 1 minute, the player moved on to the next more difficult level with the same scenario and similar design. Each game consisted of 20 levels in order for its duration to be approximately 20 minutes.

Our initial plan was to develop only two different versions of this maze game: a structured one, with very limited freedom of movement and equally limited freeform gameplay, and a freeform one, with much higher freedom of movement and equally higher freeform gameplay. Still, considering that there may be a limit, probably dependent on player skills, over which, with more freedom, the flow and effectiveness might decrease, we decided to develop one more third version with intermediate levels of freedom of movement and freeform gameplay.

The design was within-subjects single factor with three conditions:

(a) Structured game: Game with the lower degree of freeform gameplay (G1): This game allows players' movements only in two different paths, reducing in this manner their options and restricting their freeform movement.

(b) Semi-structured game: Game with an average degree of freeform gameplay (G2): This game provides clearly more alternative paths in comparison to G1. However, players' movement options remain fewer in comparison to the G3.

(c) Freeform game: Game with the higher degree of freeform gameplay (G3): This game gives the players complete freeform movement in any direction they desire as compared to the other two game versions.
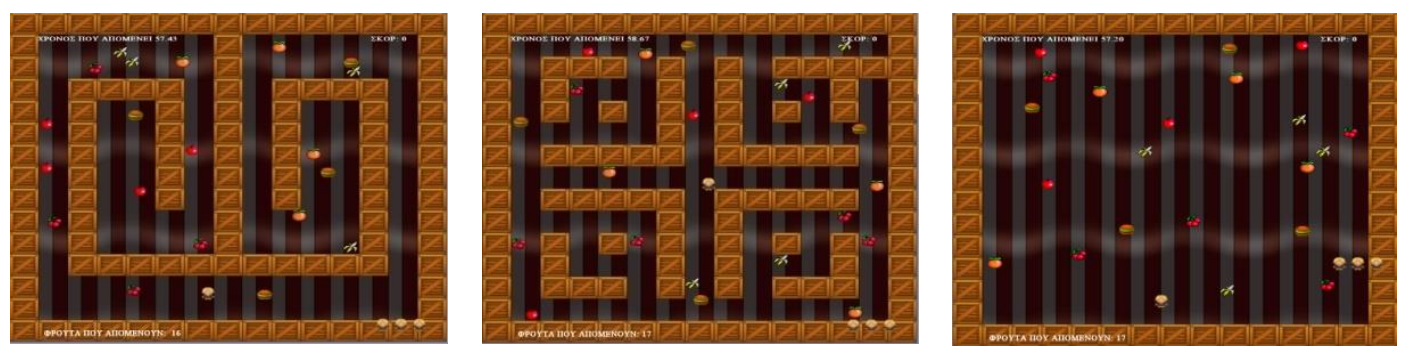

Figure 1: The three different versions of a maze game with different degrees of freedom of movement and freeform gameplay, from lower (left) to higher (right) used in our experiment.

\subsection{Data collection instruments}

There are numerous data collection instruments that could be adopted for measuring user experiences, however, it is important that the methods had been validated with children, and therefore the Fun Toolkit Read [38] Read and MacFarlane [39] was selected. The first tool is the Smileyometer, a 5 point Likert Scale, with 1 relating to 'Awful' and 5 to 'Brilliant' (see Figure 1).

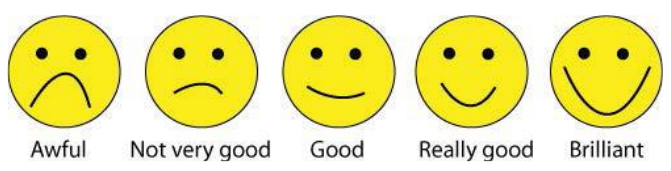

Figure 2: Smileyometer rating scale

The Smileyometer is usually used after the children interact with the technology. The rationale for using it afterwards it is assumed that the child is reporting experienced fun. The Smileyometer has been widely adopted and applied in research studies to measure satisfaction and fun as it is easy to complete and requires no writing on behalf of the children. In our study, Smileyometer values were coded in an ordinal way from 1 to 5 , where 5 represented 'brilliant' and 1 'awful'. 
The Fun Sorter requires children to rate the technology or in this instance game to a number of different constructs. The children would rank the games from the least to the most liked. In our study, Fun Sorter results were coded as 3 for the highest-ranked game and 1 for the lowest-ranked game. The Fun Sorter table used in this research is shown in Figure 2.

2. Which game ...

\begin{tabular}{|c|c|c|c|}
\hline & A lot & A moderate amount & A little \\
\hline $\begin{array}{c}\text { did you liked the } \\
\text { most }\end{array}$ & & & \\
\hline
\end{tabular}

Figure 2: The Fun Sorter table

The final tool is the Again and Again table is a table that requires the children to pick "Yes", "Maybe or "No" for each activity they have experienced. In this study the children were asked "Would you like to play this game again?" and they had to respond accordingly (Figure 4). The Again and Again table was coded as 3 for Yes, 2 for Maybe and 1 for No. Therefore, the game with the highest value would be perceived as preferred choice.

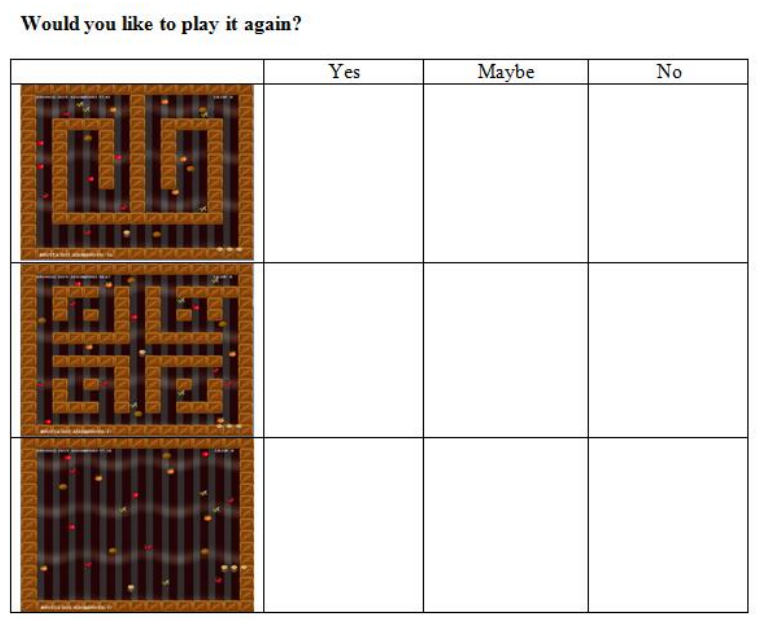

Figure 3: The Again and Again table

\section{Results}

\subsection{Different versions of the same game, which differ only in the extent of freeform gameplay, will lead to a different gaming experience.}

The Smileyometer was completed by all students $(\mathrm{t}=71)$ and the mean scores, medians and standard deviations are presented in Table 3. To determine whether there was a difference in user experience between the three games a Friedman test revealed a significant difference between the three games, $\chi^{2}=23.112, p=0.000$.

Table 3: Mean Scores, Medians and Standard Deviation for Smileyometer results

\begin{tabular}{c|c|c|c}
\hline & & \multicolumn{2}{|c}{ After } \\
\cline { 2 - 4 } & Mean & Median & SD \\
\hline Game A & 3.66 & 4.00 & $(1.16)$ \\
\hline Game B & 3.85 & 4.00 & $(1.06)$ \\
\hline Game C & 4.41 & 5.00 & $(1,17)$ \\
\hline
\end{tabular}

Furthermore, using the Fun Sorter and Again and Again tables the children were asked to rank the three games on two different criteria: the game that most liked and the game that would choose to play again. 
The mean scores and standard deviations are presented in Table 4. Also, in this case, a Friedman test revealed a significant difference between the three games for both more liked $\mathrm{x}^{2}(3$, $\mathrm{N}=71)=33,371, \mathrm{p}<0,005$, and worked the best criteria $\left(\mathrm{x}^{2}=30,043, \mathrm{p}<0,000\right)$.

Table 4: Mean Scores and Standard Deviation for two different criteria

\begin{tabular}{c|c|c|c|c}
\hline \multirow{2}{*}{} & \multicolumn{2}{|c|}{ More liked } & \multicolumn{2}{c}{ Choose to play again } \\
\cline { 2 - 5 } & Mean & SD & Mean & SD \\
\hline G1 & 1.55 & $(0.73)$ & 1.58 & $(0.79)$ \\
\hline G2 & 1.94 & $(0.67)$ & 2.04 & $(0.66)$ \\
\hline G3 & 2.51 & $(0.73)$ & 2.46 & $(0.73)$ \\
\hline
\end{tabular}

Based on the above results, there are suggestive shreds of evidence that different versions of the same game, which differ only in the extent of freeform gameplay, leads to a different gaming experience.

\subsection{From the different versions of the same game, which differ only in the extent of freeform gameplay, the one that offers the greatest extent of freeform gameplay will lead to a better gaming experience.}

Subsequently, in order to test the hypothesis H2, a post hoc Wilcoxon test for the Smileyometer was used. As it is presented in Table 5 the Post hoc Wilcoxon test revealed a significant main effect of type of game on user's experience. Children who played G3 had significantly higher rates than did children who had played G1 $(\mathrm{Z}=-4,079, \mathrm{p}=0,000)$ and $\mathrm{G} 2(\mathrm{Z}=-3,077, \mathrm{p}=0,002)$, while there were no statistically significant differences between G1 and G2.

Table 5: Game that leads to better gaming experience

\begin{tabular}{l|c|c|c}
\hline & $\mathrm{G} 2-\mathrm{G} 1$ & $\mathrm{G} 3-\mathrm{G} 1$ & $\mathrm{G} 3-\mathrm{G} 2$ \\
\hline $\mathrm{Z}$ & -1.102 & -4.079 & -3.077 \\
\hline Asymp. Sig. (2-tailed) & 0.270 & 0.000 & 0.002 \\
\hline
\end{tabular}

Furthermore, using the Fun Sorter table the children were asked to rank the games from the least to the most liked. Table 6 shows how many children ranked each game highest.

Table 6: Frequency each game was ranked first by the child on a number of criteria

\begin{tabular}{l|ccc}
\hline Children rankings & G1 & G2 & G3 \\
\hline More liked & 11 & 14 & 46 \\
\hline
\end{tabular}

The non-parametric post hoc Wilcoxon tests (Table 5) for the question which game children liked the most, revealed that $\mathrm{G} 3$ had significantly higher scores than $\mathrm{G} 2(\mathrm{Z}=-4,499, \mathrm{p}=0,012)$ and G1 A $(Z=-5,180, p=0,000)$. Furthermore, $G 2$ had significantly higher scores than $G 1(Z=-3,383$, $\mathrm{p}=0,001)$.

Table 7: Which game children liked the most?

\begin{tabular}{l|c|c|c}
\hline & $\mathrm{G} 2-\mathrm{G} 1$ & $\mathrm{G} 3-\mathrm{G} 1$ & $\mathrm{G} 3-\mathrm{G} 2$ \\
\hline $\mathrm{Z}$ & -2.499 & -5.180 & -3.383 \\
\hline Asymp. Sig. (2-tailed) & 0.012 & 0.000 & 0.001 \\
\hline
\end{tabular}

The non-parametric post hoc Wilcoxon tests (Table 8) for the question which game children choose to play again, revealed that $\mathrm{G} 3$ had significantly higher scores than $\mathrm{G} 2(\mathrm{Z}=-2,863$, $\mathrm{p}=0,004)$ and $\mathrm{G} 1 \mathrm{~A}(\mathrm{Z}=-4,595, \mathrm{p}=0,000)$, as well as, $\mathrm{G} 2$ had significantly higher scores than $\mathrm{G} 1$ $(\mathrm{Z}=-2,885, \mathrm{p}=0,004)$. 
Table 8: Which game children choose to play again?

\begin{tabular}{l|c|c|c}
\hline & $\mathrm{G} 2-\mathrm{G} 1$ & $\mathrm{G} 3-\mathrm{G} 1$ & $\mathrm{G} 3-\mathrm{G} 2$ \\
\hline $\mathrm{Z}$ & $-2.885 \mathrm{~b}$ & $-4.595 \mathrm{~b}$ & $-2.863 \mathrm{~b}$ \\
\hline Asymp. Sig. (2-tailed) & 0.004 & 0.000 & 0.004 \\
\hline
\end{tabular}

A total score was calculated for each of the games based on responses to the Smileyometer, Fun Sorter and Again and Again table. The maximum score a game could achieve was 11 and a minimum of 3.

The mean total scores were calculated based on the combined results of the tools within the Fun Toolkit with a maximum value of 14 and a minimum of 4 . For the G1 game, the mean total score was $6.79(\mathrm{SD}=1.8198)$ for the $\mathrm{G} 2$ was $7.83(\mathrm{SD}=1.8360)$ and for $\mathrm{G} 3$ was $9.38(\mathrm{SD}=2.1670)$.

The non-parametric post hoc Wilcoxon tests were performed to compare the means of each game. Results revealed that that $G 3$ had significant higher scores than $G 2(Z=-3,366, p=0,001)$ and G1 A $(Z=-5,356, p=0,000)$, as well as, $G 2$ had significant higher scores than $G 1(Z=-2,775$, $\mathrm{p}=0,006)$. The combined tools total score within the Fun Toolkit clearly show that the G3 is preferred over G2 and G1 for the various constructs measured.

Based on the above results, there are suggestive shreds of evidence that between different versions of the same game, which differ only in the extent of freeform gameplay, the one that offers the greatest extent of freeform gameplay leads to a better gaming experience.

Finally, the Spearman's correlation coefficient showed that there is a strong positive correlation between children's positive experience and the game they would choose to play again $(p=0.692, p<0.01)$. Therefore, the analysis of Spearman's correlation coefficient supports the view that there is a significant correlation between the variables of positive experience and children's willingness to play the game again: increases in the level of children's positive experience are correlated with increases in the children's willingness to play again the game.

\subsection{Impact of different game versions on players' experience across sex, age, frequency of digital game use and gaming experience}

The non-parametric Kruskal-Wallis and Mann-Whitney U tests for the total scores of the Fun Toolkit were used in order to examine the impact of different versions of the same game across various variables such as sex, grade, frequency of digital game use and gaming experience (Table 9).

Table 9: Differences across sex, grade, frequency of digital game use and gaming experience

\begin{tabular}{l}
\hline Games with significant effect of sex: \\
\hline Game $3(+)^{* *}$ \\
\hline Games with significant effect of grade: \\
\hline Game 1 (F)* \\
Game 3(M)* \\
\hline
\end{tabular}

(+) Older students liked the game better than younger

(-) Younger students liked the game better than older

(M) Boys liked the game better than girls

(F) Girls liked the game better than boys

$* \mathrm{p}<0.05$

$* * \mathrm{p}<0.01$

The statistical analysis showed that there were statistically significant differences across players' sex and age, while there was no statistically significant difference across frequency of digital game use and gaming experience.

More specifically, the Mann-Whitney $U$ test showed statistically significant difference across age for $\mathrm{G} 3 \mathrm{Z}(22,71)=22.393, \mathrm{p}=0.000$, with older students having a higher ranking mean (Mean Rank=41.16) than females (Mean Rank=30.15) and respectively for $G 1, Z(2,71)=6.481 \mathrm{p}=0.011$, with females having a higher ranking mean (Mean Rank=46.35) than younger students (Mean Rank=26.22). 
In addition, the Mann-Whitney $U$ test showed statistically significant difference across sex for $\mathrm{G} 3, \mathrm{Z}(22,71)=6.481, \mathrm{p}=0.011$, with males having a higher ranking mean (Mean Rank=41.16) than females (Mean Rank=30.15) and respectively for $G 1, Z(2,71)=6.481 \mathrm{p}=0.011$, with females having a higher ranking mean (Mean Rank=44.06) than males (Mean Rank=31.34).

These findings could indicate that games with higher levels of freeform gameplay would be better suited to male and older players, in contrast to females and younger who seem to prefer games with more formal/structured interaction.

\subsection{Importance of game features in players' preference}

The most important feature determining whether a game is funny and preferable in this research was whether or not a player had access to freeform gameplay into the game world. In order to examine which game features impact players' preference, the players were asked to say what they liked about their favorite game. An initial list was composed of all comments provided by the players. Thereafter all responses were coded into categories of similar comments. Once the data were organized, we finally identified six (6) categories. Table 10 shows grouped categories of comments that the players made about things they liked in the games. Of the reasons given for liking a game, 36.4 percent had to do with the existence of freedom of movement ("I like it because I could follow different paths"), 22.7 percent had to do with the absence of obstacles that limit players' freeform movement, 13.6 percent had to do with the ease of game ("It's easier than the others"), 10.6 percent had to do with the existence of a time limit for the completion of the mission, 15.2 percent had to do with the level of difficulty ("It's more difficult than the others"), and the remaining 1.5 percent with the existence of obstacles.

Our last table seems to show a clear relation between game features and players' preference. This becomes much more apparent by visualizing this table as a clustered bar chart, shown below.

Table 10: Importance of game features in preference for each version

\begin{tabular}{|c|c|c|c|c|c|}
\hline \multicolumn{2}{|l|}{ Feature } & \multicolumn{3}{|c|}{ Game version } & \multirow[t]{2}{*}{ Total } \\
\hline & & game1 & game2 & game3 & \\
\hline \multirow[t]{2}{*}{ Ease } & Count & 2 & 3 & 4 & 9 \\
\hline & percent of total & $3,0 \%$ & $4,5 \%$ & $6,1 \%$ & $13,6 \%$ \\
\hline \multirow[t]{2}{*}{ Freedom of movement } & Count & 0 & 4 & 20 & 24 \\
\hline & percent of total & $0,0 \%$ & $6,1 \%$ & $30,3 \%$ & $36,4 \%$ \\
\hline \multirow[t]{2}{*}{ Time limit } & Count & 1 & 2 & 4 & 7 \\
\hline & percent of total & $1,5 \%$ & $3,0 \%$ & $6,1 \%$ & $10,6 \%$ \\
\hline \multirow[t]{2}{*}{ Difficulty } & Count & 5 & 4 & 1 & 10 \\
\hline & percent of total & $7,6 \%$ & $6,1 \%$ & $1,5 \%$ & $15,2 \%$ \\
\hline \multirow[t]{2}{*}{ No obstacles } & Count & 1 & 0 & 14 & 15 \\
\hline & percent of total & $1,5 \%$ & $0,0 \%$ & $21,2 \%$ & $22,7 \%$ \\
\hline \multirow[t]{2}{*}{ Obstacles } & Count & 0 & 1 & 0 & 1 \\
\hline & percent of total & $0,0 \%$ & $1,5 \%$ & $0,0 \%$ & $1,5 \%$ \\
\hline
\end{tabular}

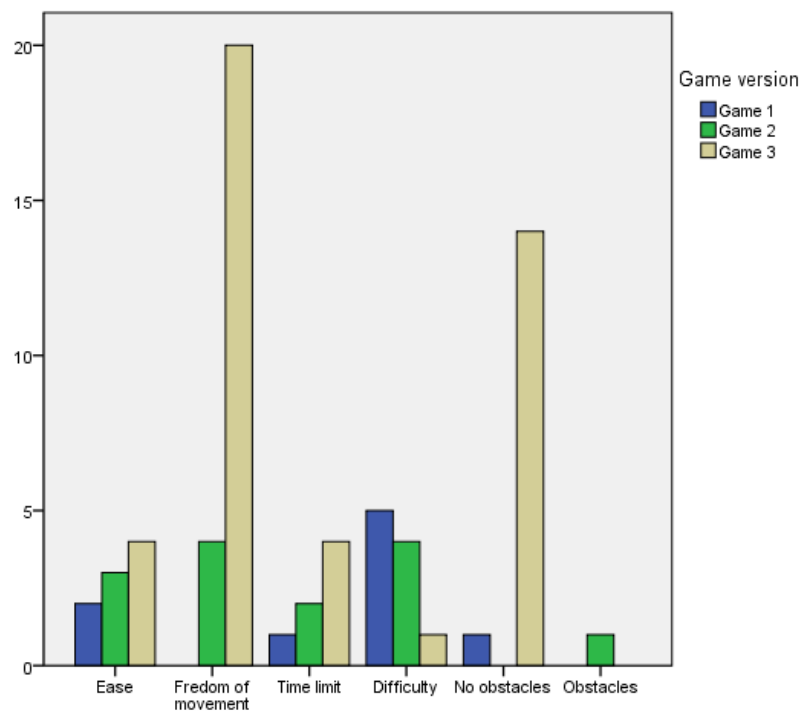

Figure 4: Game features and preferable game version 
In order to examine whether there is a causal correlation between the variables of (a) game features and (b) preferable game version, we conducted a Pearson Chi-square test $(\mathrm{x} 2=31.965$, $\mathrm{p}=0.000)$.

Table 11: Pearson Chi-square test

\begin{tabular}{l|r|r|r}
\hline & Value & df & Asymp. Sig. (2-sided) \\
\hline Pearson Chi-Square & $31.965^{\mathrm{a}}$ & 10 & 0.000 \\
\hline Likelihood Ratio & 35.811 & 10 & 0.000 \\
\hline Fisher's Exact Test & 31.385 & & 0.590 \\
\hline $\begin{array}{l}\text { Linear-by-Linear } \\
\text { Association }\end{array}$ & $0.290^{\mathrm{c}}$ & 1 & \\
\hline N of Valid Cases & & & \\
\hline
\end{tabular}

This finding indicates that there is a statistically significant correlation between these two variables and therefore, game features and preferable game version are related.

\section{Discussion and future research}

Based on findings of our previous studies, there were strong indications that one of the major factors which make games enjoyable and motivating is the freedom of choice, which allows the players to act, to create their own narrative experience and game story within a game.

Given that the games used in previous studies had different structural characteristics, it can reasonably be argued that there are other game characteristics, apart from freedom of choice, which might affect gaming experience and generate the statistical differences between the games, such as the game story, the aesthetics of the game world, the winning or losing states, the reward and score system, as well as the interaction mechanisms with the game world elements.

Therefore, in the context of this follow-up study, we decided to use three game versions that are identical to each other except for the feature of freedom of choice (lower, average, higher degree of freedom of choice). To be more exact, we chose to implement the notion of freedom of choice with freeform gameplay and, to be even more exact, with freeform movement.

With this research design we attempted to neutralize all these factors that differentiate the majority of games apart from freeform gameplay, in order to explore whether more and more freeform gameplay is always better or, in other words, should the objective of serious game design be to maximize freeform gameplay at all costs?

In light of the above, the findings of the present research study become more important considering that the game with the highest level of freeform gameplay led to better gaming experience when compared to games with average or lower level of freeform gameplay. Furthermore, the research findings showed that increases in the level of children's positive experience are correlated with increases in the children's willingness to play again the game.

As the findings of this study are in total agreement with the results reported by previous studies $[1,40]$, we propose a new theory about the significant role of the concept of freeform gameplay, which is a direct factor of freedom of choice, in what we call gaming experience. The question that arises is why freedom of choice is so appealing? The data from this experiment do not answer that question, but the analysis above suggests a number of possibilities.

The simplest answer to this question would be that children like freeform games more than formally structured ones. However, this explanation is too simplistic to be reliable. Below we will try to explain and interpret the children's preferences, not just by theoretical speculation, but based on our research findings, with a view to suggesting answers to this question:

(a) Firstly, the research showed that children liked the most and chose to play again freeform game (G3), which had the higher level of freeform gameplay. It was no surprise to find that each time the feature of freeform gameplay was limited, the game decreased slightly in appeal. We speculate that this happened because children were feeling free to explore the game world, more than in the semi-structured game (G2) and much more than in the structured game (G1).

(b) Secondly, the existence of freeform movement makes the freeform game (G3) more interesting than the other two versions. In contrast, when the player's choices are limited, this affects the gaming experience, as the game becomes more boring. This finding is directly correlated with Csíkszentmihalyi's Flow Theory. According to Csíkszentmihalyi [41], to achieve a flow state, a balance must be struck between the challenge of the task and the skill of the 
performer. Players can experience relaxation when their skill level is very high and the task challenge is very low. Conversely, players can experience anxiety when their skill level is very low and the task challenge is very high. Therefore, the most significant application of this finding in practice is that the concept of freeform gameplay (and thus of freedom of choice) is extremely important to create funny and motivating digital games on the condition that freeform gameplay is carefully designed in order to be interesting and meaningful to the player. Otherwise, the game would be less interesting and funny. Additionally, as we have mentioned [39] it should be emphasized that there may be a limit, over which too much freeform gameplay may deprive them of interesting constraints which, like challenges, play an integral role in the emergence of engagement, whereas at the same time too less freeform gameplay may indeed deprive players of interesting challenges. In this respect, the optimal level of freeform gameplay for a serious game design may well not be neither the maximum nor the minimum one, but rather an intermediate level that somehow balances a right mix of freedoms and limits so that engagement and fun are maximized.

(c) Thirdly, the greater level of freeform gameplay makes the freeform game (G3) much interesting to the players because this feature enriches players' choice for movement. Players have the choice to follow the direction they find most interesting or easier or even more useful and beneficial for the development of the game. Some of these choices are personal and tied to the player's gaming style.

\section{Concluding remarks}

Beginning with the assumption that different versions of the same game, which differ only in the extent of freeform gameplay, will lead to different gaming experience, the results of this study interpret and explain the findings from previous studies in a simple practical level, which shows an important implication: That if we have a digital game which we have created or are able to modify, we can improve gaming experience by customizing the extent of freeform gameplay according to actual players' needs.. This can be a very important tool in the hands of:

(a) game designers (of entertainment and serious games alike) as well as

(b) teachers who use digital games for learning purposes within gamified learning processes (which can themselves be improved along characteristics of freeform play).

It must be mentioned that the research conducted thus far has faced a number of limitations. Firstly, the generalizability of the results must be carefully approached since the study was conducted in a specific context (primary school) due to our research focus. Consequently, additional work is needed to determine whether or not the results may be valid with other samples, including other school contexts and age groups, as well as adults. Secondly, a self-report method was used to measure players' preferences, so some of the results might have common method biases.

This effort is contextualized within a broader research plan for using digital games as learning frameworks. Further research in this direction includes issues such as:

(a) formalizing a concept of game structure, and be able to evaluate its presence/absence in different digital games; more specifically, the research aims at the formalization and, eventually, at the quantitative assessment of a concept of game structure in freeform and formally structured digital games, through representing the gameplay flow and states on diagrammatic formalisms such as State Transition Diagrams, and trying to arrive at typologies that will allow to place different digital games at various points on an axis between free creativity and rule-bound complexity,

(b) formalizing a concept of player engagement in digital games and be able to evaluate the engagement produced by different digital games for kindergarten and primary school players; in this respect, and with a view to exploiting the knowledge already available in this area, the research aims at being able to assess player engagement using a variety of available tools such as observation and questionnaires and emerging approaches such as facial expression recognition or biofeedback analysis,

(c) exploring the elements of game mechanics that digital games should have in order to exhibit a game structure that leads to optimal player engagement; the research intends, on the long term, to develop and validate a heuristic framework for designing optimally formally structured, and thus more engaging, digital games,

(d) selecting and/or designing digital games for language learning for preschool and primary school children that exhibit this optimal game structure; the research aims at arriving, on the long 
run, to formulate and evaluate guidelines for selecting and/or designing digital games for learning which can exhibit an optimal structure and thus lead to an optimal engagement, and

(e) studying the learning outcomes of preschool and primary school children on language learning while playing these digital games, with a view to exploring and maximizing the effectiveness of freeform and formally structured digital games for language learning.

A common theme cross-cutting all these directions of further research work has to do with the limits of freeform gameplay in digital games, as a factor for creating games that offer better experience and higher engagement. The findings of this study provide evidence that serious games should be customized, in terms of optimizing freeform gameplay, in order to fit players' needs. The exploration of an optimum level of freeform gameplay is one of the most interesting directions of research that we would like to pursue.

\section{References}

[1] Kirginas, S., \& Gouscos, D., "Exploring the Impact of Free-Form and Structured Digital Games on the Player Experience of Kindergarten and Primary School Students", In D. Russell, \& J. Laffey (Eds.), Handbook of Research on Gaming Trends in P-12 Education (pp. 394420). Hershey, PA: Information Science Reference, 2016. https://doi.org/10.4018/978-1-46669629-7.ch019

[2] Egenfeldt-Nielsen, S., Smith, J. and Tosca, S., Understanding Video Games: The Essential Introduction, London: Routledge, 2008.

[3] Almeida, S., Veloso, A., Roque, L., Mealha, O., \& Moura A., "The Video Game and Player in a Gameplay Experience Model Proposal”. In Proceedings of Videojogos 2013 - 6th Annual Conference in the Science and Art of Video Games. Coimbra, Portugal: University of Coimbra, Portugal, 2013.

[4] Rollings, A., Morris, D., Game Architecture and Design. Scottsdale, AZ: Coriolis Group, 2000.

[5] Salen, K., \& Zimmerman, E., Rules of play: Game design fundamentals. Cambridge, MA: MIT Press, 2004.

[6] Rollings, A., \& Adams. E., Fundamentals of Game Design. Prentice Hall, 2006.

[7] Rommeswinkel, H., Measuring freedom in games. University of St.Gallen Law \& Economics Working Paper, 2014.

[8] Sen, A., Freedom of Choice: Concept and Content. European Economic Review, 32, pp. 269-294, 1998. https://doi.org/10.1016/0014-2921(88)90173-0

[9] Klopfer, E., Osterweil, S., \& Salen, K., Moving learning games forward. Education Arcade. Boston, MA: Education Arcade. Retrieved from The Education Arcade Retrieved June 2, 2017, from: http://education.mit.edu/papers/MovingLearningGamesForward_EdArcade.pdf , 2009.

[10] Björk, S., Holopainen, J., Patterns in Game Design. Charles River Media, 2004.

[11] Rollings, A., \& Adams, E., Andrew Rollings and Ernest Adams on Game Design. Indianapolis, IN: New Riders, 2003.

[12] Spector, W., "Another Narrative Fallacy: Games are About Choice”, Retrieved May 31, 2017, from:http://www.gamasutra.com/blogs/WarrenSpector/20150812/250785/Another_Narrative_ Fallacy_Games_are_About_Choice.php, 2015.

[13] Prensky, M., Digital Game-Based Learning, McGraw-Hill Pub. Co., 2004.

[14] Rouse, R., Game Design Theory and Practice. (2nd Ed.) Plano, TX: Wordware Publishing, Inc, 2005.

[15] Caillois, R., Man, Play, Game, [1958]. Chicago, IL: University of Illinois Press, 2001. (Original work published 1958).

[16] Frasca, G., "Simulation Versus Narrative: Introduction to Ludology", Retrieved January 23, 2016, from: http://www.ludology.org/articles/VGT_final.pdf, 2003.

[17] McGregor, G., "Terra ludus, terra paidia, terra prefab: spatialization of play in videogames \& virtual worlds". In Proceedings of the 5th Australasian Conference on Interactive Entertainment, New York, ACM, 2008. https://doi.org/10.1145/1514402.1514407

[18] Bateman, C., "The anarchy of paidia". Retrieved November 21, 2016, from: http://onlyagame.typepad.com/only_a_game/2005/12/the_anarchy_of_1.html, 2005.

[19] Juul, J., Half-Real: Video Games between Real Rules and Fictional Worlds. Cambridge, MA: MIT Press, 2005. 
[20] Mitgutsch, K., Digital Play-Based Learning. A philosophical-pedagogical perspective on learning and playing in computer games. Journal for Information Technology Studies as Human Science 9(3), 18-36, 2008.

[21] Morrison, A., Viller, S., Mitchell, P., "Building sensitizing terms to understand free-play in open-ended interactive art environments". In Proceedings of SIGCHI Conference of Human Factors in Computing Systems, Vancouver, Canada, 7-12 May, 2011. CHI'11. ACM, New York, NY, 2335-2344, 2011.

[22] Carse, J.P., Finite and infinite games: A vision of life as play and possibility. Ballantine Books, 1987.

[23] Abt C., Serious Games, New York, Viking Press, 1970.

[24] Bellotti, F., Berta, R., De Gloria, A., Designing effective serious games: opportunities and challenges for research, International Journal of Emerging Technologies in Learning, vol. 5, pp. 22-35, 2010. https://doi.org/10.3991/ijet.v5s3.1500

[25] Bellotti, F., Berta, R., De Gloria, A., Ott, M., Arnab, S., De Freitas, S., Kiili, K., "Designing Serious Games for education: from Pedagogical principles to Game Mechanisms", In Gouscos D. and Meimaris M. (Eds.), Proceedings of 5th European Conference on Game-Based Learning, Oct 2011, Athens, Greece. Academic Publ. Ltd, Reading, UK, pp.26-34, 2011.

[26] Sliney, A., Murphy, D., “JDoc: A serious game for medical learning”, in ACHI '08 Proceedings of the First International Conference on Advances in Computer-Human Interaction, pp. 131-136, IEEE, 2008. https://doi.org/10.1109/ACHI.2008.50

[27] Slater, M., Khanna, P., Mortensen, J., Yu, I., Visual realism enhances realistic response in an immersive virtual environment, Computer Graphics and Applications, IEEE, 29(3), 76-84, 2009 https://doi.org/10.1109/MCG.2009.55

[28] Qin, J., Chui, Y. P., Pang, W. M., Choi, K. S., Heng, P. A., Learning blood management in orthopedic surgery through gameplay, Computer Graphics and Applications, IEEE, 30(2), 4557, 2010. https://doi.org/10.1109/MCG.2009.83

[29] Freeman, D., Creating emotions in games. New Riders, 2003.

[30] Gajadhar, B., de Kort, Y.A.W., and IJsselsteijn, W.A. "Shared fun is doubled fun: player enjoyment as a function of social setting”. In P. Markopoulos, B. de Ruyter, W. IJsselsteijn, \& D. Rowland (Eds.), Fun and Games (pp. 106-117). New York: Springer, 2009.

[31] Malone, T.W., \& Lepper, M.R. Making Learning Fun: A Taxonomy of Intrinsic Motivations for Learning, In R.E. Snow \& M.J. Farr (Eds.), Aptitute, Learning and Instruction: III. Conative and affective process analyses (pp. 223-253) Hilsdale, NJ: Erlbaum, 1987.

[32] Bellotti, F. , Ott, M. , Arnab, S. , Berta, R. , de Freitas, S. , Kiili, K. and De Gloria, A. "Designing Serious Games for Education: From Pedagogical Principles to Game Mechanisms" In: D. Gouscos and M. Meimaris (Eds). ECGBL 2011: 5th European Conference on Games Based Learning. . Academic Publishing Limited, 26-34, 2011.

[33] Malone, T. W. Toward a theory of intrinsically motivating instruction, Cognitive Science, Vol. 5 No. 4, 1981. https://doi.org/10.1207/s15516709cog0504_2

[34] Malone, T. W. "Heuristics for designing enjoyable user interfaces: Lessons from computer games". In Proceedings of the 1982 Conference on Human Factors in Computing Systems (Gaithersburg, Maryland, United States, March 15 - 17, 1982). New York, NY: ACM, 1982. https://doi.org/10.1145/800049.801756

[35] Kirschner, P.A., Sweller, J., Clark, R.E., Why minimal guidance during instruction does not work: An analysis of the failure of constructivist, discovery, problem-based, experiential, and inquiry based teaching, Educational Psychologist, 41, 75-86, 2006. https://doi.org/10.1207/s15326985ep4102_1

[36] Habgood, M. P. J., "Zombie Division: a methodological case study for the evaluation of gamebased learning". In: 9th European Conference on Games Based Learning: ECGBL 2015, Steinkjer, Norway, 8-9 October 2015.

[37] Habgood, M.J. and Ainsworth, S.E., Motivating children to learn effectively: Exploring the value of intrinsic integration in educational games. The Journal of the Learning Sciences, 20(2), pp. 169-206, 2011. https://doi.org/10.1080/10508406.2010.508029

[38] Read, J., \& MacFarlane, S., Measuring Fun - Usability Testing for Children. Computers and Fun 3, York: England, 2000.

[39] Read, J.C., 2008. Validating the Fun Toolkit: an instrument for measuring children's opinion of technology. Cognition, Technology and Work, 10(2): p. 119-128. https://doi.org/10.1007/s10111-007-0069-9

[40] Kirginas, S., \& Gouscos, D., Development and Validation of a Questionnaire to Measure Perceptions of Freedom of Choice in Digital Games. The International Journal of Serious 
Games, Vol. 3, Nr. 2, April-June 2016, pp. 29-45, Serious Games Society, 2016. http://dx.doi.org/10.17083/ijsg.v3i2.120

[41] Csíkszentmihályi, M., Flow: The Psychology of Optimal Experience. New York, NY: Harper \& Row Publishers, Inc, 1990. 